\title{
Consensus for tobacco policy among former state legislators using the policy Delphi method
}

\author{
Ellen J Hahn, Mary Kay Rayens
}

\begin{abstract}
Objective-To test a novel approach for building consensus about tobacco control policies among legislators.

Design-A pilot study was conducted using a two-round, face-to-face policy Delphi method.

Participants-Randomly selected sample of 30 former Kentucky legislators (60\% participation rate).

Main outcome measure-Consensus on tobacco control and tobacco farming policies.

Results-Former state legislators were more supportive of tobacco control policies than expected, and highly supportive of lessening the state's dependence on tobacco. Former state legislators were in agreement with $43 \%$ of the second-round items for which there was no agreement at the first round, demonstrating a striking increase in consensus. With new information from their colleagues, former lawmakers became more supportive of workplace smoking restrictions, limitations on tobacco promotional items, and modest excise tax increases.

Conclusions-The policy Delphi method has the potential for building consensus for tobacco control and tobacco farming policies among state legislators. Tobacco control advocates in other states might consider using the policy Delphi method with policymakers in public and private sectors.
\end{abstract}

(Tobacco Control 1999;8:137-140)

Keywords: policy Delphi method; legislators; tobacco farming; policymaking

\section{Introduction}

Kentucky leads the nation in tobacco use, as well as in burley tobacco production. Among Kentucky adults, $31.6 \%$ smoke compared with the national average of $23.6 \% .^{1}$ Burley tobacco yielded over US $\$ 704$ million in 1996, making it the state's primary legal cash crop. ${ }^{2}$ The purpose of this report is to describe former Kentucky state legislators' opinions about tobacco policy and to discuss the use of a novel approach for building consensus. The policy Delphi method was used to explore opinions about tobacco control and tobacco farming policies. This pilot study formed the foundation for a subsequent policy Delphi study with current state legislators.
Studies clearly document public support in the United States for health policies to reduce the harm caused by tobacco products. Public policy in many states, however, has failed to keep up with public opinion. Other than voting records and media portrayals, little is known about public policymakers' opinions about tobacco issues. One exception was a 1994 survey of North Carolina, Texas, and Vermont legislators' attitudes toward tobacco and voting intentions which revealed support for youth access laws. ${ }^{3}$ In the study reported here, former state legislators were interviewed face-to-face in a two-round policy Delphi study. The report illustrates the potential use of the policy Delphi method for building consensus about tobacco policy among lawmakers.

The policy Delphi method is a systematic forecasting procedure for obtaining, exchanging, and developing informed opinion on a particular topic. ${ }^{4}$ It is unique because it allows the investigator to collect data and describe agreement about specific policy options among key players in the policy decision situation. The policy Delphi method was originally developed by the RAND Corporation in the late $1940 \mathrm{~s}^{5}$ and has been used to examine and to develop consensus on a variety of issues including drug policy, ${ }^{6}$ education, ${ }^{78}$ nursing administration, ${ }^{9}$ and military policies. ${ }^{10}$ The policy Delphi method is a multistage process involving the initial measurement of opinions (the first round), followed by data analysis, design of a new questionnaire, and a second measurement of opinions (the second round). ${ }^{11}$ This same process can be repeated until consensus is reached or saturation of opinion occurs. In the first round, divergence of opinions is typical. Consensus is more likely to occur with subsequent rounds.

The Delphi method encourages convergence toward agreement. ${ }^{11}{ }^{12}$ Taking part in the Delphi process can be a highly motivating experience for participants. The policy Delphi method has an advantage over more traditional interviewing because it incorporates education and consensus building into the process of data collection. In most Delphi studies, experts are asked to generate items through a first-round, open-ended procedure ${ }^{1314}$ using mailed questionnaires rather than face-to-face meetings. ${ }^{11}$ However, using face-to-face interviewing rather than mailed questionnaires greatly increases participation in the policy Delphi process. ${ }^{15}$ With legislators, mailed questionnaires have lower response rates $(32 \%)^{16}$ compared with face-to-face interviews $(84 \%))^{3}$ 
Table 1 Examples of Delphi items, first and second rounds

\begin{tabular}{|c|c|c|c|c|}
\hline \multirow[b]{2}{*}{ Category } & \multicolumn{2}{|l|}{ First-round items } & \multicolumn{2}{|l|}{ Second-round items } \\
\hline & Item & Score & Item & Score \\
\hline Reliability & $\begin{array}{l}\text { "Studies show that when businesses go } \\
\text { smoke-free, there are no reductions in } \\
\text { business profits. In your opinion, how reliable } \\
\text { is this information?" }\end{array}$ & $\begin{array}{l}\text { Certainly reliable (4) to } \\
\text { Unreliable (1) }\end{array}$ & & \\
\hline Importance & $\begin{array}{l}\text { "A recent study showed that almost all } \\
\text { Jefferson County residents want restaurants } \\
\text { to be smoke-free. How important is the issue } \\
\text { of smoking in restaurants relative to others?" }\end{array}$ & $\begin{array}{l}\text { Very important (4) to } \\
\text { Unimportant }(1)\end{array}$ & & \\
\hline Desirability & $\begin{array}{l}\text { "One goal of state policy might be to promote } \\
\text { smoke-free restaurants. How desirable is this } \\
\text { objective?" }\end{array}$ & $\begin{array}{l}\text { Very desirable (4) to } \\
\text { Very undesirable (1) }\end{array}$ & $\begin{array}{l}\text { " } 67 \% \text { believed that promoting smoke-free } \\
\text { restaurants was desirable in Kentucky. In your } \\
\text { opinion, how desirable is this objective?" }\end{array}$ & $\begin{array}{l}\text { Very desirable (4) to } \\
\text { Very undesirable (1) }\end{array}$ \\
\hline Feasibility & $\begin{array}{l}\text { "The majority of Kentuckians think smoking } \\
\text { in small restaurants should be banned. How } \\
\text { feasible is this policy option for Kentucky?" }\end{array}$ & $\begin{array}{l}\text { Definitely feasible (4) to } \\
\text { Definitely not feasible (1) }\end{array}$ & $\begin{array}{l}\text { " } 53 \% \text { thought banning smoking in small } \\
\text { restaurants was feasible in Kentucky. In your } \\
\text { opinion, how feasible is this policy option?" }\end{array}$ & $\begin{array}{l}\text { Definitely feasible (4) to } \\
\text { Definitely not feasible (1) }\end{array}$ \\
\hline
\end{tabular}

\section{Methods}

SAMPLE

The sample of 30 former legislators was randomly selected from a total of 55 eligible former legislators who had not served in the Kentucky general assembly since 1994. There was a $60 \%$ participation rate among the accessible population of former legislators. Most were men with a mean age of 59 (SD 11) years. All were white. Almost two-thirds had college degrees or had completed postgraduate work. Approximately three-quarters were Democrats. Participants had served an average of 11.9 (SD 7.9) years in the general assembly. Only two participants were current smokers; $57 \%$ were former smokers. Three participants were current spit tobacco users; $20 \%$ were former users. Of the participants, $83 \%$ were still involved in politics to some degree. When in office, participants represented 60 of the 120 counties in Kentucky. Almost half of these counties grew over three million pounds (1360 tonnes) of tobacco each in 1994 (Kentucky agriculture statistics 1994-1995). Over a third (43\%) of the participants had grown or leased tobacco; $27 \%$ were current growers/leasers. Sixty per cent reported having accepted campaign contributions from tobacco companies.

INSTRUMENT

First-round Delphi questions usually include sets of four categories of items: reliability, importance, desirability, and feasibility. Reliability items provide the respondent with a statistic or estimate of a future event. Participants are asked to judge the reliability of the data. For importance items, respondents rank issues in terms of their significance relative to others. Desirability items elicit opinions about the benefits of certain policy goals. For feasibility items, respondents identify the likelihood that specific options might reach policy goals. Because policy Delphi questions are designed to elicit conflict and disagreement as well as to clarify opinions, the response categories do not permit neutral answers. An example of a set of Delphi questions used in this study is presented in table 1 .

The interview guide used in this study included reliability, importance, desirability, and feasibility items, for a total of 84 first-round and 37 second-round items. Tobacco control items included issues or policies related to youth access, clean indoor air, marketing and advertising, smoking cessation, excise taxes, and litigation. Items on the future of tobacco farming included farm diversification, agricultural infrastructure, and the federal price support programme. Current data on tobacco control and tobacco farming issues were compiled from the literature and formed the basis for the interview items. An expert panel of agricultural and health leaders reviewed the items for accuracy and content appropriateness. The second-round interview guide consisted of the desirability and feasibility items for which there was no agreement on the first round. Table 1 displays an example of two second-round items and demonstrates how data collected in the first round were incorporated into the second-round interview guide.

PROCEDURE

Participants were recruited via letters and telephone calls. Between one and five telephone calls were needed to establish contact and recruit participants. Six of the subjects could not be contacted by telephone; seven others refused to participate (14\% refusal rate). Each former legislator participated in two interviews at the legislator's residence, office, or other convenient location. First-round interviews lasting approximately 45 minutes were conducted by an experienced male interviewer; second-round interviews lasted 25-30 minutes. Each interview item was read aloud, and the lawmaker was asked to respond. Data were collected before the announcement of the proposed national settlement between state attorneys general and the tobacco companies on 20 June 1997.

Interquartile deviations (IQD) were used to assess the degree of consensus on each item. The IQD is the absolute value of the difference between the 75 th and 25 th percentiles with smaller values indicating higher degrees of consensus. IQDs ranged from 0.00 (most agreement) to 3.00 (least agreement). Items with an IQD >1.00 indicated a lack of consensus and were retained for the second interview. In addition to determining consensus on individual items, items were summarised as mean scores according to type of policy issue across all four Delphi categories. Mean scale scores determined relative degree of agreement on youth access, clean indoor air, marketing and advertising, smoking cessation, excise taxes, litigation, and tobacco farming. 
Table 2 Mean summary scores for tobacco control and tobacco farming policy options, first round

\begin{tabular}{llll}
\hline Scale & Items & Mean & SD \\
\hline Farming & 17 & 3.1 & 0.3 \\
Clean indoor air & 15 & 3.0 & 0.5 \\
Smoking cessation & 5 & 2.9 & 0.6 \\
Youth access & 17 & 2.9 & 0.4 \\
Marketing & 9 & 2.8 & 0.5 \\
Litigation & 9 & 2.6 & 0.6 \\
Excise tax & 12 & 2.5 & 0.5 \\
\hline
\end{tabular}

Responses range from 4 (positive) to 1 (negative).

\section{Results}

At the first round, there was consensus on 15 of 67 tobacco control items (22\%), and on seven of 17 tobacco farming items (41\%). At the second round, there was agreement on an additional 16 items of the 37 items common to both rounds (43\%). Responses to 11 of these items became more supportive of tobacco control, and responses to two tobacco farming items indicated increased support. Responses to three tobacco control items became more negative between the first and second rounds.

At the first round, former lawmakers were most supportive of economic policies related to tobacco farming, followed by clean indoor air policies, smoking cessation treatment availability, youth access measures, marketing restrictions, litigation, and excise tax increases (table 2). At the second round, only individual item responses were considered. Summary scores were not compiled at the second round because of the small number of items in each of the seven issue areas. Table 3 summarises responses on selected tobacco control and tobacco farming items at both rounds. Participants viewed the two-round process favourably, and they appreciated the differentiation between the "desirability" of a policy goal and the "feasibility" of adopting a specific policy option.

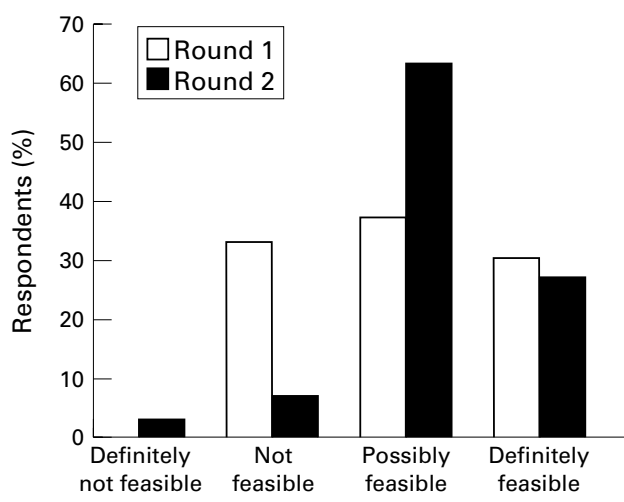

Feasibility that Kentucky could restrict workplace smoking $(n=30)$.

CONSENSUS ON TOBACCO CONTROL POLICY

Of all the tobacco control policy issues, former lawmakers were most supportive of strengthening clean indoor air laws. Almost all (87\%) participants believed that children's exposure to secondhand smoke was a very important issue. Most former lawmakers agreed that the state should guarantee smoke-free environments for children (table 3). They also agreed at the second round that the general assembly would be likely to ban tobacco use on school property and at all school events. Although there was no consensus at the first round about the feasibility of restricting workplace smoking, $90 \%$ agreed at the second round that the general assembly was likely to adopt laws restricting workplace smoking (figure). Almost all participants thought Kentucky should increase the availability of effective smoking cessation programmes.

There was $100 \%$ agreement that Kentucky should strengthen the current youth access law. Former lawmakers thought it was likely that the general assembly would ban the sale of cigarettes from vending machines, would require merchants to keep tobacco products

Table 3 Average opinions about tobacco policies: selected items, both rounds

\begin{tabular}{|c|c|c|c|c|c|c|}
\hline \multirow[b]{2}{*}{ Item } & \multicolumn{3}{|c|}{ First round $(n=30)$} & \multicolumn{3}{|c|}{ Second round $(n=30)$} \\
\hline & Mean & $S D$ & $\%$ Positive $\dagger$ & Mean & $S D$ & $\%$ Positive \\
\hline \multicolumn{7}{|l|}{ Clean indoor air } \\
\hline Guarantee smoke-free environments for children & 3.2 & 0.8 & $83.3^{\star}$ & NA & NA & NA \\
\hline Ban tobacco on school property & 3.1 & 0.9 & 76.7 & 3.5 & 0.6 & $96.7^{\star}$ \\
\hline \multicolumn{7}{|l|}{ Smoking cessation } \\
\hline Make effective cessation programmes available & 3.2 & 0.7 & $90.0^{\star}$ & NA & NA & NA \\
\hline \multicolumn{7}{|l|}{ Youth access } \\
\hline Ban cigarette vending machines & 3.1 & 0.8 & $80.0^{\star}$ & NA & NA & NA \\
\hline Require merchants keep tobacco behind counter & 3.0 & 1.0 & 70.0 & 3.2 & 0.7 & $83.3^{\star}$ \\
\hline Prohibit sale of single cigarettes & 2.9 & 1.0 & 72.4 & 3.3 & 0.8 & $82.8^{\star}$ \\
\hline Revoke licences of tobacco retailers who sell to minors & 2.9 & 0.7 & 73.3 & 2.9 & 0.8 & $76.7^{\star}$ \\
\hline \multicolumn{7}{|l|}{ Marketing } \\
\hline Restrict distribution of tobacco promotional items & 2.9 & 0.8 & 73.3 & 3.5 & 0.6 & $96.7^{\star}$ \\
\hline Restrict point-of-sale advertising & 2.8 & 0.8 & 63.3 & 3.0 & 0.7 & $86.7^{\star}$ \\
\hline \multicolumn{7}{|l|}{ Excise taxes } \\
\hline Increase tax for farm diversification & 2.9 & 0.7 & $76.7^{\star}$ & NA & NA & NA \\
\hline Tax all tobacco products at the same rate & 2.8 & 0.8 & 66.7 & 3.1 & 0.6 & $86.7^{\star}$ \\
\hline Impose a tax on smokeless products & 2.6 & 0.7 & 63.3 & 3.0 & 0.6 & $83.3^{\star}$ \\
\hline Double tax on cigarettes to $\$ 0.06$ per pack & NA & NA & NA & 2.9 & 0.7 & $83.3^{\star}$ \\
\hline \multicolumn{7}{|l|}{ Litigation } \\
\hline Should sue to recover tobacco-related healthcare costs & 2.5 & 0.9 & 50.0 & 2.5 & 1.0 & 43.3 \\
\hline Likely to sue tobacco companies for Medicaid costs & 2.2 & 1.0 & 33.3 & 2.3 & 0.7 & 33.3 \\
\hline \multicolumn{7}{|l|}{ Tobacco farming } \\
\hline Develop alternative agricultural enterprises & 3.7 & 0.4 & $100.0^{\star}$ & NA & NA & NA \\
\hline Require tobacco companies to contribute to reinvestment fund & 2.7 & 0.7 & 70.0 & 3.2 & 0.7 & $90.0^{\star}$ \\
\hline
\end{tabular}

$\star$ Denotes agreement using interquartile deviation method.

†\% Positive includes responses to "very desirable" or "desirable" and "very likely" or "likely".

$\mathrm{NA}=$ not applicable. 
behind the counter, would prohibit the sale of single cigarettes, and would suspend the licences of tobacco retailers who sell to minors. Although there was no consensus about restricting the distribution of tobacco promotional items to children at the first round, almost all former lawmakers agreed at the second round that Kentucky should do so. Similarly, former lawmakers agreed at the second round that the general assembly was likely to restrict point-of-sale advertising that appeals to children. Regarding excise tax increases, there was agreement at the first round on only one excise tax policy item-raising the tax for improvement of agricultural infrastructure. At the second round, however, former legislators agreed that all tobacco products should be taxed at the same rate and that Kentucky could impose a tax on smokeless tobacco products and double the tax to $\$ 0.06$ per pack. However, there was consensus (93\% of respondents) at the second round that the general assembly would not be likely to raise the cigarette tax to the national average. Regarding political financing by tobacco companies, $83 \%$ of former legislators did not think it was likely that the general assembly would prohibit elected officials from accepting campaign contributions. Similarly, $87 \%$ did not think it likely that the state would divest holdings in tobacco company stocks. Former legislators did not agree on issues related to litigation at either round. Although half of the participants thought Kentucky should take legal action to recover healthcare costs attributable to tobacco, only a third felt this was a feasible course of action.

CONSENSUS ON TOBACCO FARMING POLICY

All former lawmakers thought the state should improve the agricultural infrastructure by supporting the production of other commodities, and $80 \%$ thought it was likely that the general assembly would allocate general funds for this. Similarly, all were supportive of the development of alternative agricultural enterprises. Of the participants, $83 \%$ thought the general assembly would be likely to allocate more funds for farm diversification and $80 \%$ agreed that providing low-interest loans to help farmers diversify was a feasible policy option. Although there was no agreement at the first round that the general assembly could require tobacco companies to contribute to a reinvestment fund for farm diversification, there was consensus at the second round that this policy option was feasible.

\section{Conclusions}

In the light of Kentucky's long tradition of economic and cultural dependence on tobacco, former state legislators were more supportive of tobacco control policies than expected. Former lawmakers were also highly supportive of lessening the state's dependence on tobacco and thought it likely that the Kentucky general assembly would adopt policies favouring farm diversification and agricultural infrastructure. The fact that former state legislators were in agreement with $43 \%$ of the second-round items for which there was no agreement at the first round showed a striking increase in consensus. Although findings demonstrated agreement for and against tobacco control, 13 of 16 consensus items at the second round were pro-tobacco control. With new information from their colleagues, former lawmakers became more supportive of workplace smoking restrictions, limitations on tobacco promotional items, and modest excise tax increases.

Because this study was a pilot for a subsequent study with current state legislators, ${ }^{17}$ a small sample size was used. The fact that the participants were no longer serving in the general assembly allowed them to be less influenced by political pressures, and perhaps more optimistic about the feasibility of tobacco control and tobacco farming policies.

Findings from this study and preliminary results from our subsequent study of current legislators reveal that the policy Delphi method may be a promising tool for building consensus and planning legislative tobacco control initiatives. The policy Delphi process allows tobacco control advocates to determine areas of consensus at the first round, and build consensus by giving new information during the second interview. The fact that this policy Delphi study was a positive experience for former lawmakers from a tobacco-growing state is encouraging. Tobacco control advocates in other states might consider using the policy Delphi method with policymakers in public and private sectors.

The authors wish to thank the Kentucky health and agricultural communities for their guidance on this project. Financial support was provided by the American Lung Association of Kentucky. Special thanks to Dr Lynne Hall for her expert assistance in editing the manuscript.

1 US Centers for Disease Control and Prevention. Statespecific prevalence of cigarette smoking among adults, and adolescents' exposure to environmental tobacco smokeUnited States, 1996. MMWR 1997;46:1038-43.

2 Kentucky Agricultural Statistics Service. Kentucky agricultural statistics, 1996-1997. Louisville, Kentucky: Kentucky Department of Agriculture, 1997:8-100.

3 Goldstein AO, Cohen JR, Flynn BS, et al. State legislators' attitudes and voting intentions toward tobacco control legislation. Am f Public Health 1997;87:1197-200.

4 Dunn WN. Public policy analysis. Englewood Cliffs, New Jersey: Prentice-Hall, 1981.

5 Dalkey N, Helmer O. An experimental application of the Delphi method to the use of experts. Manage Sci 1963;9:458-67.

6 Rainhorn JD, Brudon-Jakobowicz P, Reich MR. Priorities for pharmaceutical policies in developing countries: results of a Delphi survey. Bull WHO 1994;72:257-64.

7 Cookson PS. Charting the unknown: Delphi and policy Delphi strategies for international co-operation. Int $\mathscr{f}$ Lifelong Educ 1986;5:3-13.

8 Raskin MS. The Delphi study in field instruction revisited: expert consensus on issues and research priorities. I Soc Work Educ 1994;30:75-89.

9 Jairath N, Weinstein J. The Delphi methodology (part one): a useful administrative approach. Can $\mathcal{F}$ Nurs Admin 1994; 7:29-42.

10 Linstone HA, Turoff M, eds. The Delphi method: techniques and application. Reading, Massachusetts: Addison-Wesley, 1975.

11 McKenna HP. The Delphi technique: a worthwhile research approach for nursing? $\mathcal{f} A d v$ Nurs 1994;19:1221-5.

12 Lyons H. Solutions by consensus. Health Soc Serv 7 $1981 ; 2: 1515-16$

13 Spinelli T. The Delphi decision-making process. F Psychol 1983;113:73-80.

14 Turoff $M$. The design of a policy Delphi. Tech Forecast Soc Change 1970;2:149-71.

15 McKenna HP. The selection by ward managers of an appropriate nursing model for long-stay psychiatric patient care. $\mathcal{F}$ Adv Nurs 1989;14:762-75.

16 Buchanan RJ, Ohsfeldt RL, Tobias D, et al. Medicaid coverage of AIDS-related care: attitudes of state legislators serving on health-related committees. AIDS Public Policy $\mathcal{f}$ 1991;6:135-41.

17 Hahn E, Toumey CP, Rayens MK, et al. Kentucky legislators' views on tobacco policy. Am ₹ Prev Med 1999;16:81-8. 